no escape. Post operative progress uneventful. On 29/4/21 the chamber was formed, section smooth, eye quiet.

The fundus showed a large splash of white (old haemorrhage) to nasal side of disc. There was no cupping. Fine vitreous opacities were present.

On $5 / 5 / 21$ he was discharged.

R.E.V. with a plus $10=5 / 20$. L.E.V. with a plus $10=5 / 30$. Of six cases of microphthalmus seen in the past year (of which I retained notes), only one could possibly come under the heading microcornea as defined by Mr. Collins. In this case, although the corneae were small $(9 \mathrm{~mm}$. vertical diameter), the iris normal on either side, the scleral portions of the globe apparently normal in size, and the eyes symmetrical, one could not exclude all congenital abnormalities as there was cataract. The other five cases all showed either colobomata or irregularities in the size or shape of the globe as a whole, and asymmetry.

\title{
ANNOTATIONS
}

\section{The Teaching and Examination of Medical Students in Ophthalmology}

The Report of the Examination Committee of the General Medical Council, considered on November 26, contained the following clause (Lancet, December 10, p. 1,238) :-

"Diseases of the Eye, Ear, and Throat. The inspectors in Medicine and Surgery recommended that Candidates' knowledge of these diseases should either be efficiently tested in the final examination, or should produce evidence that they had been sufficiently instructed and tested as to their knowledge of these subjects."

It will be remembered that the Council of British Ophthalmologists issued a report on the Teaching and Examination of Medical Students in Ophthalmology in 1919 (this Journal, April, 1919). Annotations on this subject appeared in the Journal in the June, July, August, and October numbers of that year, and in the July number of 1920 . The recommendations of the Council of British Ophthalmologists were as follows :-

1.) No student shall be admitted to the final examination, qualifying to practise medicine, unless he has attended an ophthalmic clinic for not less than six hours a week during a period 
of three months, and has attended a course of systematic instruction in ophthalmology.

(2.) No student shall be considered to have passed the qualifying examination unless he has shown a sound knowledge of practical ophthalmology in an examination conducted by ophthalmic surgeons.

The General Medical Council considered this Report and recommended " that every student should be required to attend a course of practical instruction in ophthalmology of not less than ten weeks' duration, and that no student should be admitted to the final examination unless he presents a certificate to the effect that he has attended such a course regularly and that his work in connection therewith has reached a satisfactory standard." Every one recognizes the futility of mere "signing up" in ophthalmology. Students, with an already overcrowded curriculum, will not devote much attention to a subject upon which it is unlikely that they will be examined. As a result they often become qualified with complete ignorance of such conditions as ophthalmia neonatorum, which, if inefficiently treated, are the cause of much defective vision or even blindness. Now that its own Examination Committee have come round to the opinion of ophthalmologists on this subject there is some hope of the acceptation of the British Council's recommendations by the General Medical Council.

Ophthalmologists are fully aware that the medical curriculum is overcrowded. Theirs is not the only subject which is crowded out : others are oto-laryngology and psychology. There is only one way of dealing adequately with the problem, viz., a complete revision of the curriculum. Hitherto, the curriculum has been intended to cover the requirements of all medical students, whether they are fated to become general practitioners or hospital physicians and surgeons. As a result the curriculum is unsatisfactory for both classes. In our opinion the qualifying curriculum and examinations should be directed to the turning out of thoroughly efficient general practitioners, and further study and examination should be demanded of those who specialize in the various branches of medicine and surgery. In this manner the time occupied by the curriculum for the registrable qualification might even be shortened. We are fully aware of the practical difficulties attending such a revision, but we are convinced that they are not insuperable. We respectfully suggest that the General Medical Council should take the bull by the horns and attack the whole problem anew on a broad basis. 